\title{
Dor - Aspectos Fisiopatológicos
}

José Brenha Ribeiro Sobrinho *

\section{RESUMO}

Neste artigo foram revistos os diversos níveis de integração do fenômeno nociceptivo, bem como o interrelacionamento da nocicepção com os demais elementos sensoriais, mnésticos e motivacionais. Enfatizou-se neste artigo o caráter multidimensional do fenômeno doloroso.

\section{SUMMARY}

This article reviewed the diferent levels of integration of the nociception, as well as the interrelationship of the nociception with the other modalities of sensation and with the motivacional and mnestics elements. This paper emphasized the multidimensional character of the nociceptive phenomenon.

Dor é sem dúvida a mais comum das queixas e o mais comum dos sintomas. Segundo dados estatísticos americanos metade das consultas a clínicos são motivadas primariamente por quadros álgicos que refletem os mais variados processos mórbidos.

Entretanto caracterizar e quantificar estes sintomas é extremamente difícil uma vez que dor é muito mais uma percepção do que uma sensação simples, e como sabemos as percepções estão sujeitas a influências multifatoriais como o estado físico do paciente, suas experiências prévias com eventos semelhantes, a antecipação da situação a ser vivenciada etc.

No presente artigo vamos rever os mecanismos envolvidos na percepção dolorosa, abordando tanto os mecanismos periféricos como centrais da nocicepção, bem como os mecanismos periféricos e centrais que o organismo lança mão para inibíla.

Os eventos que a nível periférico desencadeiam estímulos nociceptivos são esquematizados na seqüência de gravuras.

No esquema A temos que a ação agressora nos tecidos (seja esta por um mecanismo físico ou químico) provoca pela destruição celular liberação de potássio e no meio extracelular a síntese de prostaglandina. A ruptura ou o aumento da permeabilidade dos vasos provoca extravasamento de bradicinina.

Enquanto que a bradicinina e o potássio (entre outras) são algogênicos, as prostaglandinas aumentam a sensibilidade das terminações nociceptivas.

No esquema B vemos a ativação secundária provocada pela atuação de reflexos axônicos que fazem liberar nas terminações nervosas a substância $\mathrm{P}$ o que embora não provoque dor, induz ao extravasamento de líquido pelos vasos e liberação de histamina e serotonina pelos mastócitos e plaquetas respectivamente.

Estas substâncias provocam diminuição do limiar de 
excitabilidade das fibras nociceptivas e as estimulam, o que provoca maior afluxo de estímulos álgicos e para o SNC ao mesmo tempo mais liberação de substância $\mathrm{P}$, formando-se assim ascendem pelos tratos espinotalâmicos.

É a nível medular, mais precisamente no corno posterior da medula que os estímulos nociceptivos sofrem influxos inibitórios tanto de origem

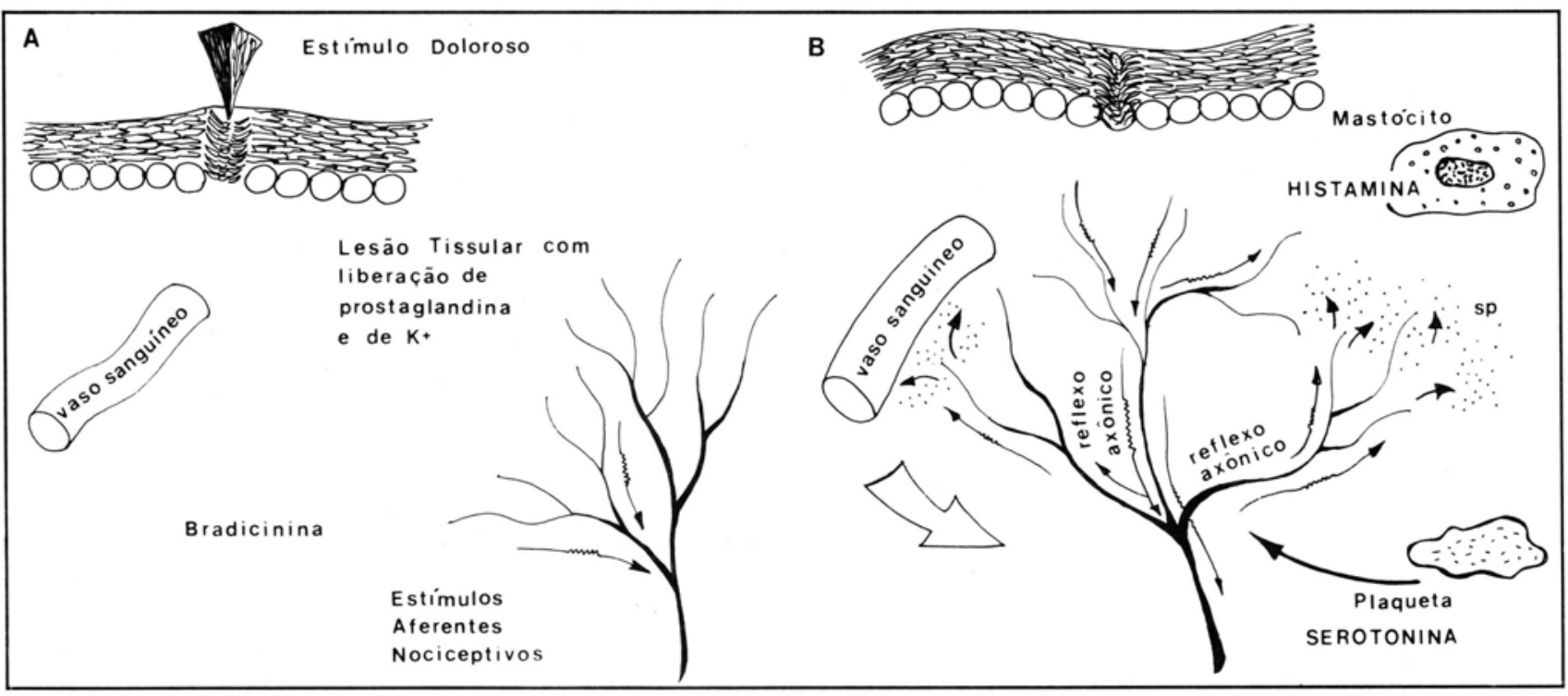

um mecanismo reverberante, auto-perpetuante que leva inclusive à disseminação gradual da hiperalgesia e/ou dolorimento.C

Este mecanismo multiplicador periférico é inibido provavelmente pela ação periférica, sobre as terminações nervosas livres, de opióides endógenos liberados pelas células macrofágicas e pelos linfócitos no local da lesão. Estas substâncias opióides acoplam-se nos receptores tipo mu e delta presentes na superfície dos axônios. Este acoplamento tem por resultado tanto o aumento do limiar de excitabilidade das fibras nociceptivas como também a diminuição da liberação da substância P.

Os estímulos nociceptivos são transportados pelas fibrasamielínicas tipo $\mathrm{C}$ e pelas fibras tipo A, pobremente mielinizadas, que tendo os corpos celulares nos gânglios das raízes dorsais enviam axônios para porção posterolateral da medula, formando o fascículo dorso lateral ou de Lissauer. Neste fascículo as fibras A, e C dividemse em um segmento descendente curto e um ascendente longo enviando ramos transversais a cada segmento medular, ramos estes que terminarão nas lâminas I, II e V de Rexed.

Neste ponto as fibras cruzam a medula e periférica como de origem central.

Partindo do segmento periférico temos que as fibras largas que carreiam estímulos de tato e de propriocepção consciente, enviam colaterais que fazem sinopse com neurônios internunciais

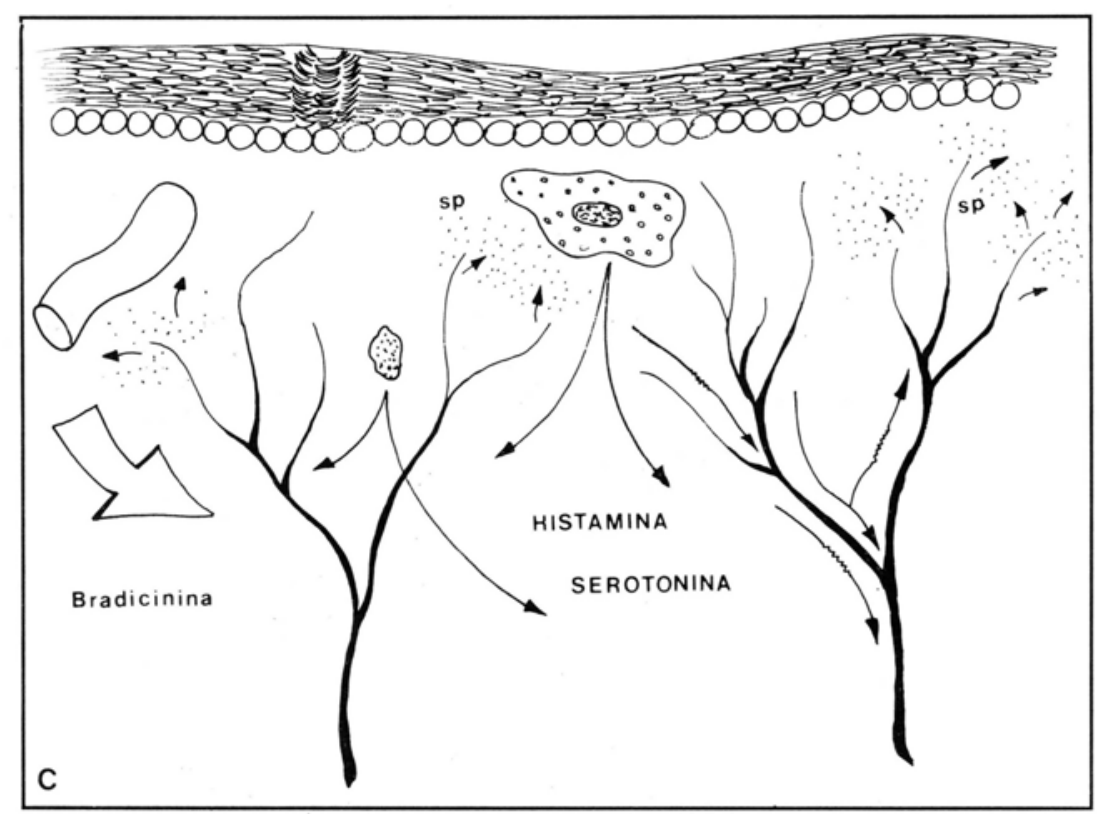




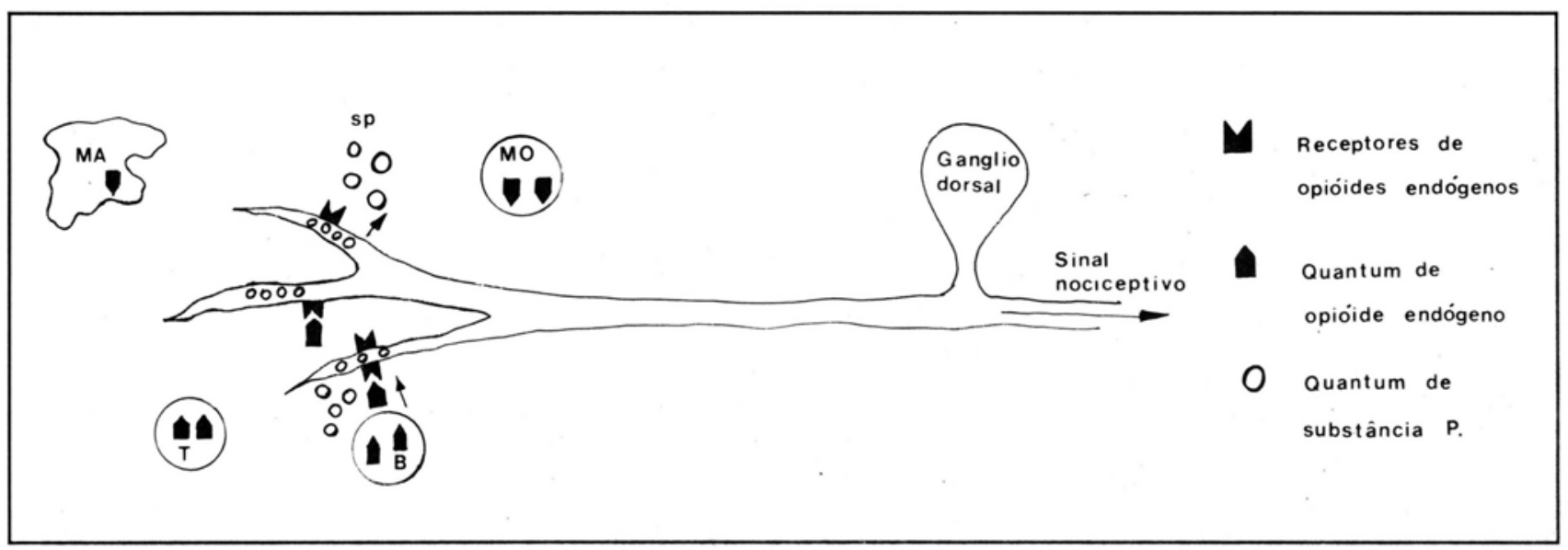

É também a nível medular que agem as terminações dos axônios oriundos do tronco cerebral, por intermédio dos mediadores químicos serotonina, noradrenalina e encefalina, nas células dos neurônios carriadores da nocicepção, a nível das lâminas I, II, e V de Rexed.

\section{Sistema Espinotalâmico}

Os axônicos nociceptivos que formam os tratos espinotalâmicos terminam em vários núcleos do tronco cerebral e talâmicos.

O trato espinotalâmico pode ser dividido conceitualmente em dois sistemas baseados nestas conexões.

1- O Sistema espinotalâmico direto que transporta informações sensoriais discriminativas sobre dor diretamente aos núcleos talâmicos, e um sistema filogeneticamente mais antigo, o sistema espinoretinotalâmico que termina de maneira difusa nos núcleos da formação reticular do tronco cerebral e nos núcleos mediais do tálamo.

As fibras, o sistema espinotalâmico direto que terminam no tálamo parecem ter importância para a percepção consciente das sensações nociceptivas. Este sistema termina de uma maneira ordenada dentro do núcleo ventral posterolateral (VPL). O campo terminal do trato espinotalâmico no VPL se sobrepõe ao influxo de estímulo de propriocepção consciente e tato que são oriundos das colunas dorsais/leminiscos mediais. O padrão organizado das terminações e a convergência das fibras carreadoras de informações táteis com as fibras carreadoras de dor para o VPL podem ser importantes para a percepção dos aspectos discriminativos-sensoriais da dor, incluindo a localização natureza e intensidade do estímulo nociceptivo.

Corroborando esta hipótese, as células do VPL projetam-se principalmente no córtex somatosensorial primário.
2- O sistema mais difuso espinoreticutalâmico pode mediar os aspectos autonômicos e afetivos da dor. As fibras espinoreticulares terminam em diversos níveis da formação reticular do tronco cerebral formando parte de um sistema polissináptico que termina nos núcleos talâmicos mediais (núcleo central lateral e núcleo parafacicular).

As células pertencentes ao trato espinoreticulotalâmico freqüentemente apresentam grandes campos aferentes dispostos de maneira bilateral que por vezes incluem toda a superfície celular. Estas células freqüentemente respondem de maneira intensa a estímulos nociceptivos. Tais células não estão provavelmente envolvidas na discriminação sensorial ou localização do estímulo doloroso, sendo mais provável que suas funções tenham a haver com as relações de orientação e de alerta ao estímulo doloroso.

\section{Vias Descentes Analgésicas}

Além das grandes vias ascendentes esboçadas anteriormente o cérebro contém vias descendentes bem desenvolvidas que visam suprimir as aferências nociceptivas. Este sistema é composto pela substância cinzenta periarquedutal mesencefálica que apresenta células com projeções descendentes que se dirige ao tronco cerebral e a medula espinal. Na realidade poucas fibras da substância periarquedutal projeta-se diretamente a nível medular.

Ao invés disso a maioria das fibras faz sinapse com os núcleos da rafe do bulbo, especialmente o núcleo "raphe magnum". Os neurônios da rafe por sua vez projetam-se na medula espinal aonde eles inibem as respostas nociceptivas dos neurônios da coluna dorsal. Estes neurônios descendentes podem potencialmente fechar o fluxo da informação nociceptiva a partir do nível da $1^{\text {a }}$ sinapse na coluna dorsal. 
A substância cinzenta periarquedutal, a rafe bulbar e as colunas dorsais da medula apresentam uma grande quantidade de peptideos opiáceos endógenos e de receptores de opiáceos. Altas densidades de receptores de opiáceos são encontrados também, nas porções mediais do tálamo e no prosencéfalo límbico.

As aminas biogênicas representam outra classe de neurotransmissores encontrados nas vias descendentes que modulam a nocicepção. Serotonina é contida e muitos dos neurônios da rafe bulbar e alguns axônios serotoninérgicos terminam diretamente nos pericários dos neurônios do trato espinotalâmico.

Uma importante via descendente inibidora da nocicepção contendo noradrenalina tem por origem o núcleo do locus ceruleus na ponte; este sistema parece inibir as respostas nociceptivas da coluna dorsal por um mecanismo adrenérgicos. Drogas que potencializam os efeitos centrais das aminas biogênicas como os antidepressivos tricíclicos podem portanto ser analgésicos adjuvantes eficientes que agem reforçando os efeitos destas vias descendentes.

Nos últimos anos foram identificados a nível bulbar mais precisamente em sua porção rostroventromedial, ao lado de neurônios formadores de vias descendentes analgésicas, células nervosas que projetando-se sobre a medula facilitam a transmissão dos estímulos álgicos.

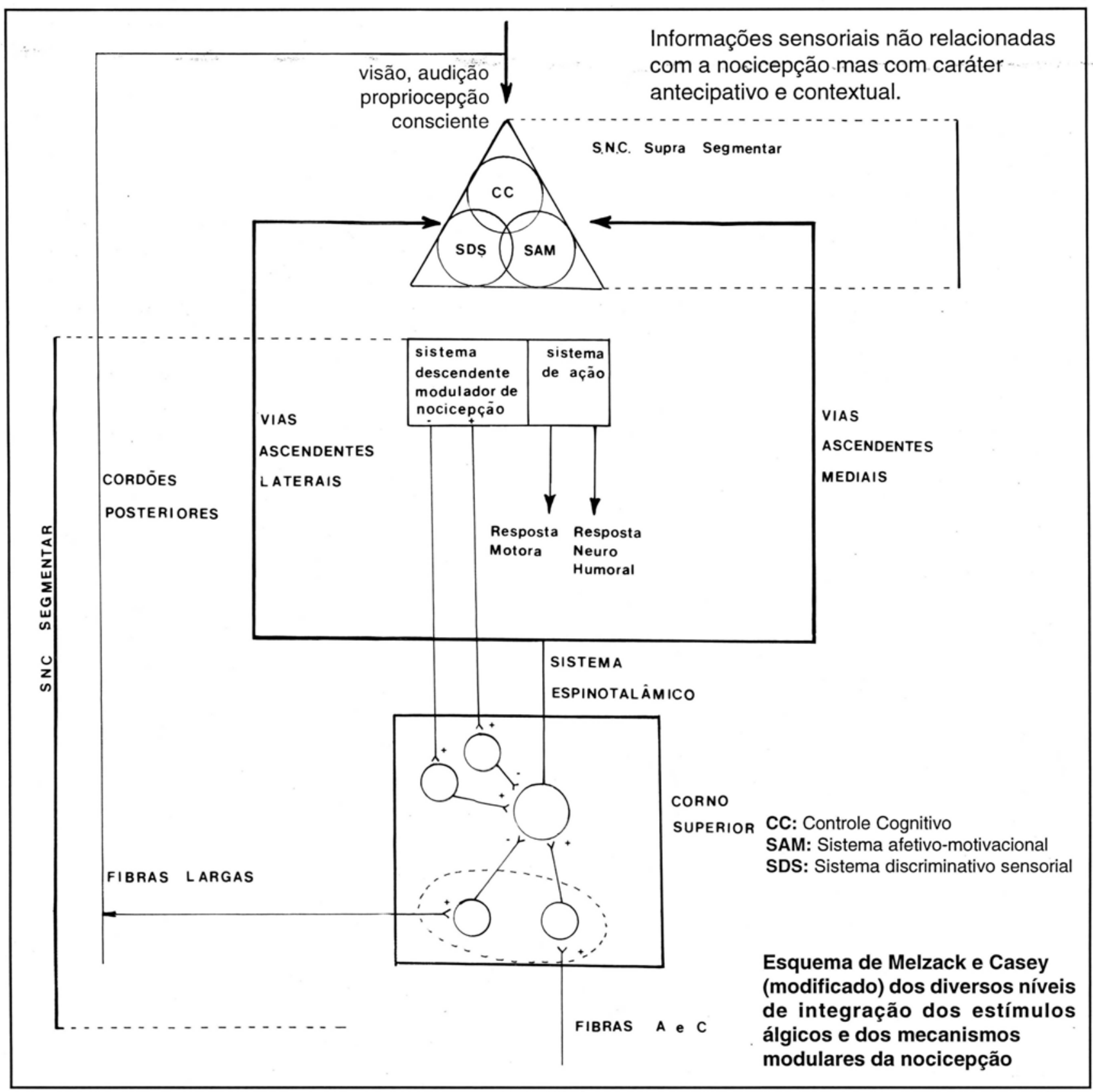


Desta maneira, vemos que tanto a nível periférico como ao nível do corno anterior da medula e em tronco cerebral existem mecanismos moduladores da dor, modulação na qual o sistema nervoso suprasegmentar certamente tem papel preponderante.

\section{A integração suprasegmentar do fenômeno nociceptivo}

A dor é uma experiência complexa, que inclui a identificação ou o reconhecimento de eventos somático-sensoriais em termos de tempo, espaço, intensidade e submodalidade (mecânica, térmica, química) e está associada com mecanismos afetivo -emocionais.

Da integração destas duas dimensões de eventos tem origem ações que tem por meta livrarse do agente algogênico, incluindo outras formas de comportamento aversivo. Na tentativa de sintetizar todas as variáveis e elementos envolvidos na nocicepção Melzack e Wall e posteriormente Melzack e Cazey hipotetizaram um esquema teórico procurando integrar os fenômenos periféricos com a atividade das estruturas suprasegmentares em seus aspectos sensóriognóstico e motivacional afetivo.

Embora este esquema não tenha a aceitação universal, é contudo o que procura englobar os vários aspectos do fenômeno nociceptivo. Apresentamos a seguir uma adaptação do esquema de 1968.

Nele os estímulos nociceptivos sofrem sua primeira modulação a nível do corno posterior da medula por intermédio de neurônios internunciais que estimulados pelas colaterais das fibras largas que ascendem pelos cordões posteriores, vão inibir os neurônios que formam os tratos espinotalâmicos. Neste mesmo nível neurônios internunciais estimulados por fibras $\mathrm{C}$ e A tem a capacidade de estimular os neurônios dos tratos espinotalâmicos. A somatória dos dois tipos antagônicos de estímulos é que causará ou não a ativação dos neurônios do sistema de nocicepção.

Este sistema se divide como vimos anteriormente em uma porção lateral e outra medial e, se projetam a nível supra segmentar, respectivamente nas estruturas responsáveis pela dimensão sensorial discriminativa e afetivo motivacional. Através de conexões recíprocas múltiplas, envolvendo tanto o evento corrente como os traços mnésticos respectivos, estes sistemas funcionais interagem simultaneamente com o sistema de controle cognitivo que integra a síntese dos estímulos nociceptivos elaborados nos dois sistemas citados, com informações não relacionadas diretamente com a nocicepção mas que estão relacionados com o contexto biológico e social em que está ocorrendo o fenômeno álgico.

Além disto este sistema de controle cognitivo tem a capacidade de influir na manipulação da informação nociceptiva antes que a mesma ocorra, através da análise de sinais (situações concretas em curso, avisos verbais ou escritos de eventos que ocorrerão em breve) que antecipam ao indivíduo o evento nociceptivo que ocorrerá, lançado mão do repertório de traços mnésticos de experiências prévias.

Da síntese resultante da atividade simultânea destes três sistemas funcionais (medular, pontino mesencefálico - e cerebral) resultam reações orgânicas que visam fornecer a resposta mais adequada para combater o fenômeno doloroso.

Podemos dividir a reação orgânica em dois eventos.

O $1^{\circ}$ é a ativação do sistema descendente de modulação da dor. Este sistema projeta-se no Sistema Nervoso Central Segmentar e de acordo com a síntese prévia das múltiplas informações poderá inibir ou mesmo facilitar o influxo de estímulos álgicos.

O $2^{\circ}$ sistema é o de ação que pode ser subdividido em sistema de ação motora e sistema de ação neuro-humoral, desencadeando as reações motoras necessárias ao escape da fonte da dor ou as contrações tônicas necessárias à imobilização do agente nociceptivo e, produzindo os eventos sistêmicos necessários à reação orgânica contra a dor e contra os efeitos lesivos provocados pelo agente nocivo, tanto a nível local como a nível geral.

Por último queremos ressaltar que a evolução no conceito do fenômeno doloroso em conseqüência dos achados experimentais acumulados nos últimos 30 anos caracterizam a nocicepção como um elemento de um extenso complexo neuro-humoral de importância capital para a preservação do indivíduo abrindo assim o horizonte de possibilidades na área da pesquisa na terapêutica da dor.

\section{Referências Bibliográficas}

1. Bonica, J. The management of pain $2^{a}$ ed. Lea \& Febiger. Philadelphia, 1990

2. Cesselin, F. Endorphines et nociception. Revue neurologique 142(8) 649-670 1986

3. Stein Christoph. Periferal mecanisms of Opioid Analgesia. Anesthesia and analgesia. 76: 182-191 1994

4. Blalack, J.E. Human Leucocit Interferon: Structural and biological relateness to adrenocorticotropic hormone and endorphines. Proceedings of the National Academy of Sciences $77 n^{\circ} 105972-5974.1980$

5. Chantraine Abrége de medicine phisique $2^{a}$ ed. Masson, 1982. 